\title{
Metastatic hypernephroma of the parotid gland
}

\author{
R. C. Percival \\ F.R.C.S.
}

\author{
J. R. N. CURT \\ F.R.C.S.
}

Surgical Unit, Salford Royal Hospital, Salford M60 9EP

\begin{abstract}
Summary
A case of metastatic hypernephroma of the right parotid gland is reported. The case presented two years before developing symptoms of her hypernephroma. The metastasis was unaffected by excision of the primary hypernephroma.

\section{Introduction}

'Clear cell' carcinoma of the kidney (hypernephroma) commonly metastasizes by vascular spread to the lungs and bones (Anderson, 1978). Numerous other sites for hypernephroma metastases have been described. However, there have been only 3 other reports of metastasis to the parotid region (Gandon et al., 1977; Smith et al., 1977; Ballanger and Ballanger, 1979).
\end{abstract}

\section{Case report}

A 71-year-old Caucasian female first presented in November 1977 with a painless swelling of the right parotid region of 9 months' duration. Examination demonstrated a pulsatile, mobile swelling situated just below the right angle of mandible, approximately $4 \mathrm{~cm}$ in diameter (Fig. 1). The swelling showed the sign of emptying. In addition, a right Horner's syndrome was noted. No bruit was heard. A routine chest X-ray showed a space-occupying lesion in the apex of the right lung. At this time the patient refused further investigation and failed to attend for review.

In October 1978 she presented to the Urology Department with painful haematuria. Intravenous pyelography showed changes consistent with a neoplasm of the left kidney. At operation a hypernephroma involving the lower pole of the left kidney was confirmed. Histology showed a clear cell carcinoma of kidney with penetration of the capsule by tumour. She made a satisfactory postoperative recovery. No investigations of the swelling in her neck were carried out at this time.

In November 1979 she complained that the swelling in the right parotid region had increased in size and agreed to further investigations.

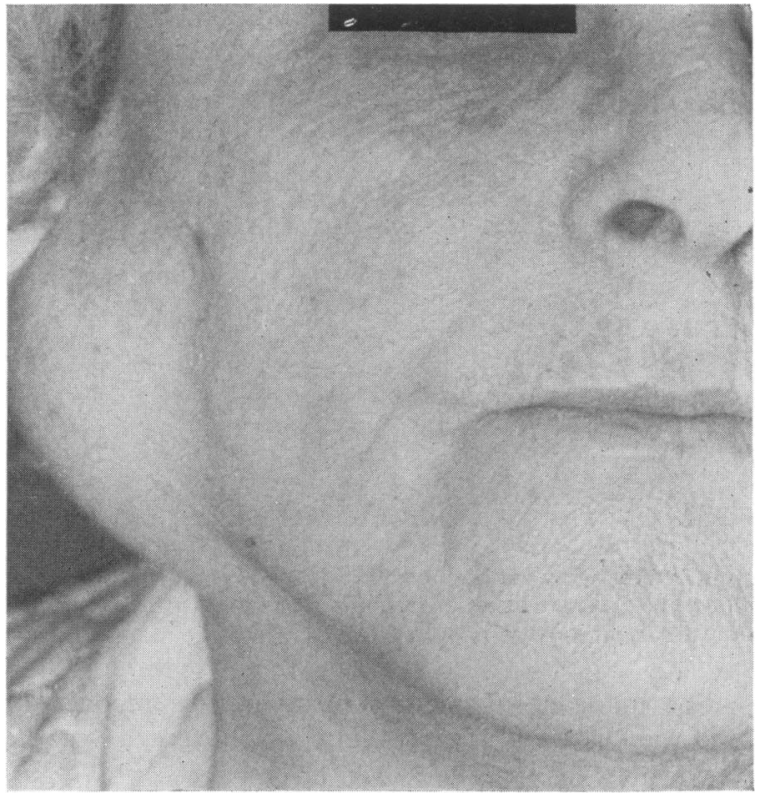

FIG. 1. Pre-operative appearance showing the right parotid swelling.

An arch aortogram showed two highly vascular lesions; one occupying the root of the neck, approximately $3 \mathrm{~cm}$ in diameter, which corresponded to the right apical opacity on the chest X-ray; the other over the angle of mandible that corresponded to her clinical swelling (Fig. 2). Despite normal biochemistry, a liver scan showed a single, very large, space-occupying lesion in the right lobe of liver. At this stage it was concluded that all 3 lesions were metastases from her left hypernephroma.

In January 1980 she had a single course of palliative radiotherapy to the right side of her neck. In view of a lack of response, it was decided mainly for cosmetic reasons that she should undergo surgery.

At operation, a well encapsulated, highly vascular neoplasm was found, external to the parotid fascia. 
The growth was enucleated and showed the macroscopic appearance of a hypernephroma as described by Anderson (1978). Histology confirmed features consistent with a metastasis from the hypernephroma previously excised.

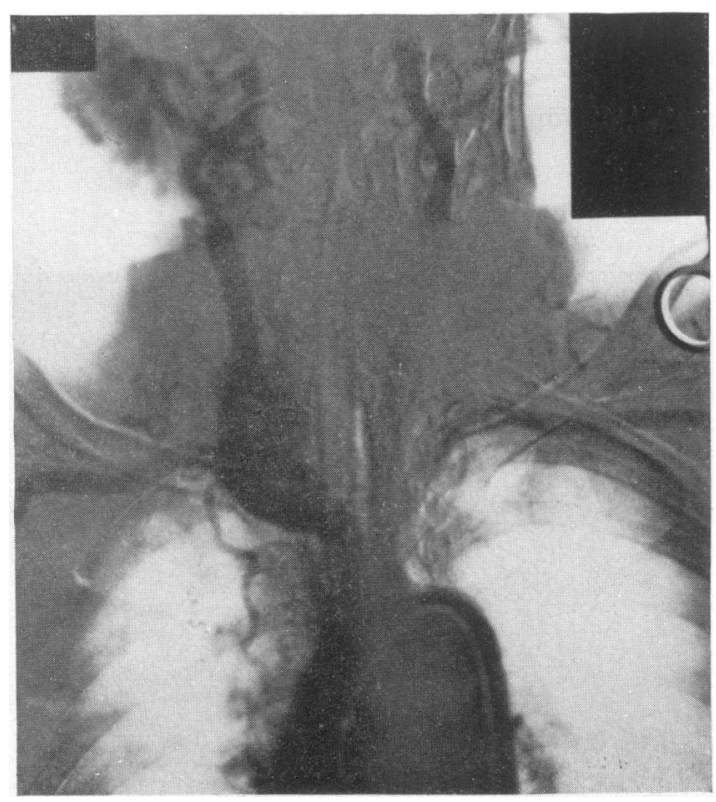

FIG. 2. An X-ray subtraction film of the arch aortogram to show the vascular blush of tumours in the right root of neck and the right parotid region.

She made a satisfactory postoperative recovery and was discharged 7 days following surgery.

\section{Discussion}

When considering the differential diagnosis of a swelling in the parotid region, diseases involving the pre-auricular lymph nodes must be considered in addition to primary tumours of the parotid. The lesions most commonly misdiagnosed as parotid tumours are lymph nodes involved with inflammatory or neoplastic disease (Nichols, Pinnock and Szymanowski, 1980).

This case is particularly unusual as the patient presented with a parotid swelling that clearly showed all the clinical features of a hypernephroma metastasis nearly two years before first developing symptoms from her renal tumour. It is clear, therefore, that if the patient had consented earlier to further investigation and surgery, this would have led to earlier diagnosis and treatment of her primary hypernephroma. Adequate treatment at that stage may have preceded the development of a large liver metastasis that at present obviates any further radical treatment policy.

Finally, in agreement with the findings of Middleton (1980) there was no regression of the metastasis following excision of the primary hypernephroma.

\section{References}

ANDERSON, J.R. (1978) The urinary system In: Muir's Textbook of Pathology (Ed by Anderson, J. R.) revised edn, p. 799. Edward Arnold Ltd, London.

Ballanger, R. \& Ballanger, P.H. (1979) A rare form of kidney cancer metastasis. Journal d'urologie et de néphré logie, 85, 548.

Gandon, J., Trotoux, J., Marandas, P. \& Calmette, T (1977) Metastasis of a carcinoma of the kidney to the salivary glands. A case of intraparotid metastasis. Annales d'oto-laryngologie, 94, 485.

Middleton, A.J. (1980) Nephrectomy in metastatic renal carcinomas. Urology Clinics North America, 7, 713.

Nichols, R.C., PinNock, L.A. \& Szymanowski, R.T. (1980) Metastases to the parotid nodes. Laryngoscope (St Louis), 90, 1324.

Smith, R.L., Davis, T.S., Kennedy, T.J., Graham, W.P. \& Miller, S.H. (1977) Metastatic malignancies of the parotid gland. American Family Physician, 66. 139. 